\title{
O CUSTO DOS DIREITOS FUNDAMENTAIS: 0 DIREITO À SAÚDE EM FRENTE ÀS TEORIAS DA RESERVA DO POSSÍVEL E DO MÍNIMO EXISTENCIAL
}

THE COST OF FUNDAMENTAL RIGHTS: THE RIGHT TO HEALTH AGAINST THE THEORY OF THE POSSIBILITY RESTRICTION AND THE EXISTENTIAL MINIMUM

\author{
Oreonnilda de Souza \\ Lourival José de Oliveira
}

\section{Resumo}

O Estado tem invocado a teoria da reserva do possível para justificar a inefetividade do direito à saúde, alegando afronta ao princípio da separação dos poderes, à repartição de competências e aos repasses orçamentários. Mesmo diante dos impactos econômicos gerados pelas decisões judiciais, verificou-se que a Lei Fundamental prevê mecanismos para a efetivação dos direitos fundamentais e para a revisão e/ou anulação de atos exorbitantes ao poder discricionário e atos de ingerência da Administração Pública, reflexos do sistema checks and balances. Os métodos utilizados foram o hipotético-dedutivo e o hermenêutico, a partir de revisão bibliográfica e pesquisa jurisprudencial do Supremo Tribunal Federal.

Palavras-chave: Direito à saúde. Mínimo existencial. Reserva do possível.

\section{Abstract}

The State has invoked the theory of the to justify the ineffectiveness of the right to health, alleging an affront to the principle of separation of powers, the sharing of competence and budgetary transfers. Even in the face of the economic impacts generated by judicial decisions, it was verified that the constituion provides mechanisms for the realization of fundamental rights and for the review and/or annulment of exorbitant acts to the discretionary power and acts of interference of the Public Administration, reflections of 
the system of checks and balances. The methods used were the hypotheticaldeductive and the hermeneutic, based on a bibliographic review and jurisprudential research of the Federal Court of Justice.

Keywords: Right to health. Existential minimum. Possibility restriction.

\section{INTRODUÇÃO}

Os direitos, para serem efetivados, geram custos financeiros e sociais ao Estado. Mas a tributação serviria para a manutenção da estrutura Estatal e, nela inserida, o custo para o desenvolvimento de políticas públicas para a realização dos direitos fundamentais sociais dos cidadãos.

Todavia, o Estado tem justificado a não concessão de prestações essenciais envolvendo os direitos sociais na ausência e/ou insuficiência de recursos. Porém, o direito à saúde pressupõe o próprio exercício do direito à vida, então, quando o Estado não cumpre as determinações constitucionais, o cidadão se socorre no Judiciário para a tutela desses direitos.

A pesquisa orbita em torno dos custos dos direitos fundamentais sociais, tomando por base o direito à saúde e as teorias da reserva do possível e do mínimo existencial. Pretende-se analisar a efetividade do direito à saúde no Brasil e os argumentos do Estado sobre a ausência ou insuficiência de recursos financeiros, invocando-se a teoria da reserva do possível em detrimento do mínimo existencial.

Para isso, necessário será encontrar respostas para alguns questionamentos: - o Supremo Tribunal Federal vem aplicando a teoria da reserva do possível nas suas decisões envolvendo prestações Estatais na área da saúde? Tal teoria poderia prevalecer em detrimento desse direito fundamental social? E, no caso, de o Supremo garantir o mínimo existencial e rechaçar a teoria da reserva do possível, haveria afronta aos preceitos e princípios constitucionais, em especial ao da separação dos poderes?

Utilizando-se o método hipotético-dedutivo, de conjecturas e refutações, e o método hermenêutico, a partir da análise sistêmica do texto constitucional, almeja-se a obtenção de resultados capazes de demonstrar a necessidade de efetivar o direito à saúde para garantir-se uma vida com o mínimo de dignidade à população. 


\section{RESERVA DO POSSÍVEL}

A teoria da reserva do possível é originária do direito alemão. Em meados de 1970, ao apreciar um caso emblemático envolvendo duas universidades, o Tribunal Constitucional Federal Alemão, inspirou-se na expressão "Limite do Orçamento" para exarar sua decisão (conhecida como Numerus Clausus - BverfGE n. 33, S. 333).

Fernando Borges Mânica (2011, p. 9) explica o caso:

[...] a Corte alemã analisou demanda judicial proposta por estudantes que não haviam sido admitidos em escolas de medicina de Hamburgo e Munique em face da política de limitação do número de vagas em cursos superiores adotada pela Alemanha em 1960. A pretensão foi fundamentada no artigo 12 da Lei Fundamental daquele Estado, segundo a qual "todos os alemães têm direito a escolher livremente sua profissão, local de trabalho e seu centro de formação". Ao decidir a questão o Tribunal Constitucional entendeu que o direito à prestação positiva - no caso aumento do número de vagas na universidade - encontra-se sujeito à reserva do possível, no sentido daquilo que o indivíduo pode esperar, de maneira racional, da sociedade. Ou seja, a argumentação adotada refere-se à razoabilidade da pretensão.

O fundamento precípuo dessa teoria, em sua origem, não vincula de forma direta e exclusiva a existência de recursos financeiros para a concretização dos direitos fundamentais sociais, mas sim propõe uma análise frente à razoabilidade daquilo que se pode exigir da sociedade para efetivação desses direitos.

Nesse sentido, esclarece Ingo Wolfgang Sarlet (2003, p. 265):

[...] a prestação reclamada deve corresponder ao que o indivíduo pode razoavelmente exigir da sociedade, de tal sorte que, mesmo em dispondo o Estado de recursos e tendo poder de disposição, não se pode falar em uma obrigação de prestar algo que não se mantenha nos limites do razoável.

Não obstante isso, a teoria da reserva do possível tem sido invocada para exprimir insuficiência de recursos denotando a impossibilidade do cumprimento das prestações estatais no fornecimento de serviços públicos envoltos aos direitos sociais, tornando-se um perigoso instrumento limitador da eficácia dos direitos a partir da condicionante "recursos 
materiais" para o fornecimento das prestações de responsabilidade do Estado, estabelecendo certa adequação desses direitos ao orçamento disponível. Em síntese, a efetivação dos direitos fundamentais sociais, incluindo-se o núcleo de direitos essenciais à vida humana, estaria condicionada a possibilidade financeira e a previsão orçamentária do Estado.

Segundo Stephen Holmes e Cass Sunstein (1999, p. 94), as necessidades humanas são infindáveis enquanto os recursos públicos são escassos. Por isso há necessidade de o Poder Público fazer escolhas no momento de implantar políticas públicas - umas são prioritárias, outras não; "taking rigths seriously means taking scarcity seriously" (Tradução livre: Levar os direitos a sério é levar a escassez a sério). A partir daí, seria justificável o não cumprimento das prestações sociais.

Porventura, poderia isso ocorrer? Poderia o Estado brasileiro invocar uma teoria, de origem alemã, criada e aplicada em um contexto totalmente diverso, para se eximir das incumbências outorgadas pela Constituição Federal? Evidente que não. O Estado deverá prover as necessidades sociais e garantir o mínimo existencial. E, nesse sentido, não haveria espaço para aplicação da teoria da reserva do possível em detrimento dos direitos fundamentais, por encontrar sérios óbices nos preceitos e princípios estatuídos pelo texto constitucional.

\section{TEORIA DOS CUSTOS DOS DIREITOS}

A dimensão econômica é, sem dúvidas, um fator relevante, mais que isso, determinante na efetivação dos direitos. Todos geram custos ao Estado, que se vale de duas fontes: uma originária e outra derivada. As receitas originárias integram os cofres públicos a partir da exploração direta de uma atividade econômica, na qual o Estado presta serviços ou administra o patrimônio público (ex. privatizações). Ao contrário, nas receitas derivadas os recursos são provenientes da tributação, sua maior fonte de recursos.

Uma das obras mais lidas e citadas sobre os custos dos direitos é a escrita por Stephen Holmes e Cass R. Sustein. A tese central defendida pelos autores é a de que todo direito tem um custo para sua realização. Por esse motivo, não existiriam direitos absolutos - a efetivação dos 
direitos fundamentais sociais depende, segundo os autores, de dois fatores: recursos financeiros suficientes originários das contribuições dos indivíduos e a administração do Estado. ${ }^{1}$

Para os autores, nenhum direito cuja eficácia dependeria de gasto Estatal poderia ser tutelado, de modo unilateral, pelo Poder Judiciário em razão das consequências orçamentárias que afetariam o Legislativo e o Executivo, gerando responsabilidades e prejuízos de outras ordens (HOLMES; SUSTEIN, 1999, p. 97). O discurso revela a possibilidade de ponderação da efetividade dos direitos fundamentais com base na escassez de recursos, isto é, a aplicação da teoria da reserva do possível.

Comprovando que todos os direitos têm custos e precisam de recursos públicos para sua realização, disserta José Casalta Nabais ([201-?], p. 12):

Do ponto de vista do seu suporte financeiro, bem podemos dizer que os clássicos direitos e liberdades, os ditos direitos negativos, são, afinal de contas, tão positivos como os outros, como os ditos direitos positivos. Pois, a menos que tais direitos e liberdades não passem de promessas piedosas, a sua realização e a sua proteção pelas autoridades públicas exigem recursos financeiros.

Inolvidável a necessidade de recursos para a realização dos direitos e das liberdades fundamentais, mas essa não é a única questão a ser discutida, pois em um país onde a carga tributária é bastante alta, o não cumprimento das diretrizes básicas de saúde e a incapacidade de prover a manutenção do mínimo vital ao cidadão brasileiro parece não encontrar guarida na ausência de recursos financeiros e sim evidenciar a ingerência e ineficiência da Administração Pública no gasto dos recursos.

Como se pode notar, embora existam fundamentos e argumentos pertinentes, a tese de Holmes e Sustein analisada no contexto sociopolítico-econômico brasileiro, à luz da Constituição Federal e, bem como, frente ao regramento infraconstitucional vigente aliados às disposições protetivas aplicáveis pelo Direito Internacional dos Direitos Humanos, não pode prosperar. Não se pode admitir a escusa Estatal na prestação dos direitos fundamentais sociais, principalmente quanto ao núcleo básico garantidor do mínimo vital. E dentro dessa ótica, está o direito à saúde. 
Nítida a responsabilidade do Estado na gestão adequada das contas públicas, na efetivação dos direitos fundamentais e na redução das desigualdades sociais e regionais. Aliás, o "Leviatã" só tem razão de existir para o atendimento dos fins sociais, promovendo o desenvolvimento sociocultural e econômico da nação, a persecução dos objetivos da República em prol do bem-estar social. Em linhas gerais, não seriam essas as principais razões justificadoras da arrecadação tributária?

Está patente aos olhos a ineficiência Estatal no cumprimento de seus deveres e o total descaso para com a efetividade dos direitos fundamentais do cidadão - a população não tem sequer o básico para a manutenção de uma vida digna.

Segundo dados e indicadores do Instituto de Pesquisa Econômica Aplicada (IPEA, 2015), a proporção de domicílios com renda domiciliar per capita inferior à linha de extrema pobreza ${ }^{2}$ embora tenha diminuído de 4,92\% em 2013 para 3,52\% em $2014^{3}$, o nível de desemprego de 7,1\% em 2013 subiu para 7,5\% em $2014 .^{4}$

A OIT (Organização Internacional do Trabalho) divulgou dados sobre o aumento do desemprego no Brasil, o informe aponta um aumento de 7,7\%. Aproximadamente 2,3 milhões de postos de trabalho serão destruídos no mundo. Desse montante 700 mil estarão em território brasileiro (CHADE, 2016). Situação que refletirá nos índices relacionados ao nível de pobreza da população e na diminuição das contribuições - sem trabalho, não há renda; sem renda, não há consumo e nem recolhimento de tributos. Se há insuficiência de recursos estatais para a realização dos direitos sociais, o problema se agravará.

Todavia, poderá o Estado reduzir, ainda mais, as prestações sociais em razão da crise econômica? Seria compreensível relegar a grande massa da população à miséria, sem trabalho, sem educação, sem saúde, sem esperança e sem dignidade alguma? Enfim, sem garantia de um mínimo capaz de propiciar uma existência digna?

Por isso, o controle jurisdicional dos atos administrativos desconformes, inadequados, insuficientes ou, até mesmo, omissivos é necessário, ainda mais "porque os direitos fundamentais, todos eles, carecem de concretização, e nenhum dos poderes públicos, nem mesmo o Judiciário, pode ficar inerte ao dever de concretização da Constituição." Negar 
essa espécie de controle é negar o próprio Estado de Direito (QUEIROZ, 2011, p. 148).

"O Estado deve ser instrumento a serviço da dignidade humana e não o contrário. É nesse amplo alcance que está a universalidade do princípio da dignidade humana e dos direitos humanos." (VITA; SILVA, 2014, p. 245).

Reservar uma parcela orçamentária para a efetivação dos direitos fundamentais sociais é medida de urgência. A Administração Pública precisa incluir tais custos como despesas fixas e se organizar para fornecer as prestações básicas necessárias a uma vida digna, reflexos do exercício da cidadania, do princípio da igualdade e da democracia.

\section{DIREITOS FUNDAMENTAIS}

Os direitos fundamentais receberam inúmeras designações terminológicas ao longo dos tempos: direitos naturais, direitos humanos, direitos do homem, direitos individuais, direitos públicos subjetivos, liberdades fundamentais, liberdades públicas e direitos fundamentais do homem.

Embora exista uma diversidade de nomenclaturas, a mais utilizada tem sido direitos fundamentais do homem, pois remete a princípios sintetizadores de uma estrutura sociopolítica normativa composta por um rol de direitos positivos, prerrogativas e garantias com escopo de garantir-se ao homem uma vida digna, igualitária, livre e mais justa. A própria Constituição Federal de 1988, no Título II, adotou a expressão "direitos fundamentais", garantindo no caput do art. 5 a inviolabilidade do direito à vida, à liberdade, à igualdade, à segurança e à propriedade.

Luiz Alberto David Araujo e Vidal Serrano Nunes Júnior (2015, p. 151) conceituam direitos fundamentais como: "uma categoria jurídica, constitucionalmente erigida e vocacionada à proteção da dignidade humana em todas as dimensões [...] prestando-se ao resguardo do ser humano na sua liberdade [...], nas suas necessidades [...] e na sua preservação".

Tais direitos são, portanto, inerentes à existência humana, são da essência do homem e, bem por isso, são imprescindíveis à sua sobrevivência - não há possibilidade de se obter qualquer realização ou qualquer 
desenvolvimento da personalidade humana sem a garantia e a efetividade dos direitos fundamentais.

Historicamente, sua formação está associada à evolução social. Os direitos fundamentais surgem em resposta às ofensas praticadas ao homem (em sua dignidade, saúde, propriedade, liberdade etc.) ${ }^{5}$ e vêm sofrendo relevantes transformações e ampliações a partir do ideário de humanização e solidariedade social.

De modo pragmático, os direitos fundamentais são compostos por direitos civis e políticos; direitos econômicos, sociais e culturais; direitos de solidariedade ou de fraternidade; direitos de manipulação genética; direitos virtuais (Internet) e o direito à paz.

Os direitos civis e políticos são aqueles relacionados à vida, liberdade, propriedade, igualdade, direitos políticos e garantias processuais. Essas liberdades de titularidade do indivíduo, segundo Paulo Bonavides (2010, p. 563) "traduzem-se como faculdades ou atributos da pessoa e ostentam uma subjetividade que é seu traço mais característico; enfim, são direitos de resistência ou de oposição perante o Estado." Por isso, são também conhecidos como direitos negativos, pressupondo ações negativas do Poder Público.

Ao contrário, os direitos econômicos, sociais e culturais demandam prestações positivas do Estado em prol do bem-estar social. Nesse momento histórico, o Poder Público deve atuar para satisfazer as necessidades sociais, efetivando-se o direito ao trabalho, à habitação, à saúde, educação e o lazer.

Os direitos fundamentais de solidariedade ou de fraternidade encerram direitos pertencentes a todos, tutelam grupos humanos, resguardam interesses difusos e comuns à humanidade em geral. São eles: o direito à autodeterminação dos povos, ao meio ambiente, à qualidade de vida, à utilização e conservação do patrimônio histórico e cultural e o direito à comunicação.

Com o avanço tecnológico e da medicina, a partir do processo de globalização, inicia-se a preocupação de tutelar os direitos sobre manipulação genética, especificamente envolvendo a pesquisa, utilização e manipulação de genes humanos. 
Consoante às argumentações de Noberto Bobbio $(1998$, p. 6):

[...] sustenta que esta geração de direitos nasceu em decorrência dos avanços no campo da engenharia genética, ao colocarem em risco a própria existência humana, por meio da manipulação do patrimônio genético, desta forma já se apresentam novas exigências que só poderiam chamar-se de quarta geração, referentes aos efeitos cada vez mais traumáticos da pesquisa biológica.

A partir da globalização das informações por intermédio da Internet, os direitos fundamentais assumem uma nova faceta: os direitos virtuais, os quais envolvem direitos originários dessa nova realidade, ou seja, desse sistema de difusão e desenvolvimento da cibernética e da internacionalização da jurisdição constitucional rompendo as fronteiras físicas e os próprios limites territoriais dos Estados soberanos.

0 direito à paz foi inserido no rol dos direitos fundamentais, com base na tese de Paulo Bonavides (2010, p. 579), cujos argumentos gravitam em torno da dignidade humana e da boa e salutar convivência entre a humanidade. Somente pela paz, consegue-se harmonizar as relações entre os povos e perpetuar a existência da humanidade, fator de segurança mundial.

Como se pode observar, a concretização dos direitos fundamentais do homem é uma preocupação das nações, cujo estudo e a efetividade são metas da disciplina de Direito Internacional dos Direitos Humanos, em virtude da necessidade de se garantir condições mínimas a uma existência humana digna, igualitária, livre e solidária.

\section{DIREITO À SAÚDE}

A Constituição da República, no art. $6^{\circ}$, elenca os direitos sociais: educação, saúde, trabalho, moradia, lazer, segurança, previdência social, proteção à maternidade e à infância e a assistência aos desamparados. Pelo teor desses direitos, percebe-se uma dimensão dos direitos fundamentais do homem, principalmente pela inter-relação com o direito à igualdade, como afirma José Afonso da Silva (2011, p. 286-287) ao conceituar os direitos sociais: 
[...] como dimensão dos direitos fundamentais do homem, são prestações positivas proporcionadas pelo Estado direta ou indiretamente, enunciadas em normas constitucionais, que possibilitam melhores condições de vida aos mais fracos, direitos que tendem a realizar a igualização de situações desiguais. São, portanto, direitos que se ligam ao direito de igualdade. Valem como pressupostos do gozo dos direitos individuais na medida em que criam condições materiais mais propícias ao auferimento da igualdade real, o que, por sua vez, proporciona condição mais compatível com o exercício efetivo da liberdade.

Sob essa ótica, depreende-se que os direitos sociais "são aqueles que reclamam do Estado um papel prestacional, de minoração das desigualdades sociais" (ARAUJO; NUNES JUNIOR, 2015, p. 277).

Para fins desse estudo, somente o direito à saúde será analisado para se chegar a resultados sobre seus custos e a aplicação, ou não, da teoria da reserva do possível frente à ausência de recursos do Estado para sua efetividade.

0 art. $2^{\circ}$ da Lei n. 8.080/90 (Lei Orgânica da Saúde) prescreve saúde como "um direito fundamental do ser humano, devendo o Estado prover as condições indispensáveis ao seu pleno exercício".

Constata-se que o direito à saúde é um direito subjetivo do cidadão e não uma ação de benemerência Estatal. Sua prestação constitui, portanto, um dever do Estado, socorrendo a quem se encontre em situação de ameaça ou dano consumado à sua saúde, na busca pela igualdade socioeconômica material (VITA; SILVA, 2014, p. 249).

Em observação as determinações constitucionais e infraconstitucionais, o Estado deve proporcionar aos cidadãos acesso ao diagnóstico preventivo, curativo e farmacêutico por meio de assistência médico-hospitalar para manutenção da saúde pública, garantindo-se, assim, o direito social à saúde de forma plena e isonômica, com aplicação do princípio da universalidade.

0 direito à saúde e o direito à vida são indissociáveis; não há vida plena, sem condições mínimas de saúde. Ademais não há dignidade humana sem a efetivação do direito à saúde. Garantir saúde à população é proteger a vida com o mínimo de dignidade. 


\section{APLICAÇÃO DO PRINCÍPIO DA DIGNIDADE HUMANA NA EFETIVAÇÃO DO DIREITO À SAÚDE}

Não há dúvidas da ligação entre direito à saúde, direito à vida e dignidade humana, princípio "mestre" para a consolidação dos direitos fundamentais na tutela do homem.

Mas qual o conceito de dignidade? Qual a sua importância?

Tailson Pires Costa (2004, p. 13), resumidamente, define dignidade humana como "o direito da pessoa conviver no ambiente social de acordo com sua própria natureza”.

Alexandre de Moraes (2014, p. 18) entende dignidade como

[...] um valor espiritual e moral inerente à pessoa, que se manifesta singularmente na autodeterminação consciente e responsável da própria vida e que traz consigo a pretensão ao respeito por parte das demais pessoas, constituindo-se um mínimo invulnerável que todo estatuto jurídico deve assegurar, de modo que, somente excepcionalmente, possam ser feitas limitações ao exercício dos direitos fundamentais, mas sempre sem menosprezar a necessária estima que merecem todas as pessoas enquanto seres humanos e a busca ao Direito à Felicidade (grifo do autor).

A dignidade, então, seria um fator interno, inerente ao ser humano; cada indivíduo, ao nascer, já a possui. E como o homem está em constante evolução, se transforma e transforma a realidade em que vive, a dignidade também sofre variações. Por isso o conceito não pode ser limitado, sendo as observações a esse respeito trazidas na tentativa de compreender, em um determinado contexto histórico, seu significado e sua abrangência.

A Constituição Federal vigente, verificando a relevância da dignidade humana, além de princípio orientador, também a consagrou como um dos fundamentos da República (art. 1ํㅡ). Logo, não há Estado Democrático de Direito sem dignidade da nação brasileira. Ela é "o núcleo do ordenamento jurídico constitucional que sustenta o Estado Democrático de Direito" (COSTA, 2004, p. 16).

Pode-se concluir que a dignidade é o primeiro fundamento do sistema constitucional e o último arcabouço da guarida dos direitos individuais, vetor direcionador para toda e qualquer interpretação de 
normas. Nesse sentido, está demonstrado o liame entre a dignidade humana e a efetividade do direito à saúde, inclusive para garantia plena do direito à vida.

\section{CUSTOS DOS DIREITOS FUNDAMENTAIS}

A instrumentalização dos direitos sociais é uma medida para o combate da marginalização, das desigualdades sociais e, em especial, a garantia do direito à saúde é meio de efetivação do direito à vida e da dignidade humana, enquanto princípio e fundamento da República.

Entretanto, a tarefa não é simples, pois, como se sabe, para se efetivar um direito, há também um custo. E, para tanto, imprescindível será dispor de recursos públicos para dar vida às políticas públicas e fazer com que tais direitos "saiam do papel". Portanto, é preciso normatizar e executar as prestações estatais na concretização dos direitos fundamentais, principalmente os sociais.

Para Robert Alexy (2002a, p. 18-20) os direitos sociais têm como correspondências imediatas prestações fáticas e prestações normativas. Isso incluiria, para uma plena eficácia das prestações materiais do Estado, ações de normatização e de execução. No caso de ausência dessas ações, serão invocadas prestações jurisdicionais no sentido de compelir o Legislativo e o Executivo a tomarem as medidas para efetivação dos direitos, pois se houver mora (sem normatização e execução) o papel do Judiciário é promover eficácia aos princípios e preceitos constitucionais.

Não se pode aplicar o "conformismo" advindo de uma situação amparada em ausência de recursos proveniente da crise político-econômica vivenciada pelo País. ${ }^{6} 0$ mínimo existencial ${ }^{7}$ deve ser provido pelo Estado; a perspectiva pós-moderna impõe sua tutela, ou seja, a proteção do "direito às condições mínimas de existência humana digna que não pode ser objeto de intervenção do Estado e que ainda exige prestações estatais positivas" (TORRES, 2009, p. 8).

O mínimo existencial pressupõe a aplicabilidade de um rol mínimo de direitos garantidores da subsistência humana. 0 direito à vida somente 
poderá ser observado se garantido um patamar mínimo que permita a manutenção e continuidade da vida de uma maneira digna. Nesse sentido, o rol de direitos e garantias consagrados pelo art. 5ํㅜ da Constituição Federal de 1988 impõe ao Estado a obrigação de oferecer condições básicas para efetividade desses direitos. Por isso, o mínimo existencial relaciona-se intimamente com a questão da justiça social.

Mas não é só isso. 0 caput do art. 60 da Constituição, também inclui no rol de direitos existenciais, aqueles necessários à vida humana, o direito à educação, à saúde, à alimentação, ao trabalho, à moradia, ao lazer, à segurança, à previdência social, à proteção à maternidade e à infância, à assistência aos desamparados. Por isso, pode-se dizer que esse "mínimo" é a matriz do princípio da dignidade da pessoa humana que, em razão de sua importância, constitui um dos fundamentos da República Federativa do Brasil (art. 1ํㅜ , inc. III).

Assim, os direitos considerados essenciais à vida humana, àqueles integrantes desse núcleo mínimo para existência do homem, são os direitos sociais, os direitos econômicos e os direitos culturais, os quais não podem ficar somente no plano teórico, mas devem atingir a todo indivíduo de forma igualitária.

O Estado demonstra total ineficiência no fornecimento do mínimo existencial constitucional e, no intento de legitimar ou justificar sua omissão e incompetência, lança mão do discurso da falta ou da insuficiência de receita orçamentária responsáveis pela inaplicabilidade dos direitos fundamentais e sociais. Argumentos inadmissíveis em um país com uma alta carga tributária como o Brasil, ainda mais com as comprovações de desvio de recursos pela "rede de corrupção" envolvendo o governo e os parlamentares.

Com relação ao direito à saúde, o Brasil está dentre os países da América Latina com menor investimento público nessa área. Os gastos com serviços públicos de saúde pela União corresponderam em menos de 1,8\% do PIB (Produto Interno Bruto) desde o ano de 2000 (IPEA, 2015, p. 161).

Falta investimento e as consequências podem ser fatais, muitas pessoas estão morrendo acometidas por enfermidades que poderiam ser prevenidas. 
Não há dúvidas, o SUS padece de insuficiência crônica de recursos financeiros, mas também enfrenta sérios problemas de gestão e ineficiência, fatores determinantes na qualidade dos serviços, cujas estruturas físicas (aparelhos e instalações) estão sucateadas e cujo o número de profissionais da rede pública de saúde é insuficiente diante da demanda da população. No mês de setembro de 2014, existiam aproximadamente 20 mil leitos de UTI (Unidade de Terapia Intensiva) disponíveis na rede pública de saúde, quantidade praticamente similar ao setor privado (planos e seguros de saúde), que atende a cerca de $25 \%$ da população (IPEA, 2015, p. 171).

Uma coisa é certa, o Estado precisa desenvolver políticas públicas e planejar suas receitas para que as disposições constitucionais e os objetivos fundamentais da República (art. $3^{\text {}}$ ) sejam concretizados. Afinal, não é essa a finalidade precípua de sua criação? Organizar seus elementos (povo, território e soberania) com vistas ao bem-estar coletivo?

Para Gilmar Ferreira Mendes, Inocêncio Mártires Coelho e Paulo Gustavo Gonet Branco (2008, p. 711),

[...] apesar da realidade da escassez de recursos para bancar políticas públicas de redução de desigualdades, é possível, sim, estabelecer prioridades entre as diversas metas a atingir, racionalizando a sua utilização, a partir da ideia de que determinados gastos, de menor premência social, podem ser diferidos, em favor de outros, reputados indispensáveis e urgentes afinal de contas, todos sabemos que a fome não pode esperar -, quando mais não seja por força do princípio da dignidade da pessoa humana, que, sendo o valor-fonte dos demais valores, está acima de quaisquer outros, acaso positivados nos textos constitucionais (grifo do autor).

Em razão disso, a teoria da reserva do possível ou da ineficiência de financiamentos deve ser vista com cautela e, no caso específico do direito à saúde, rechaçada por envolver direito fundamental que, no caso de colisão, deverá prevalecer em razão de sua própria natureza de perpetuação da vida humana.

Não há de se olvidar que os direitos sociais, além do custo econômico, também possuem custos sociais. Uma escolha privilegia um setor em detrimento de outro; a destinação de recursos para efetivar um direito certamente acarretará na diminuição ou, até mesmo, na exclusão, de 
outro. A destinação orçamentária é um reflexo de tudo aquilo que o governo e o Congresso julgam necessário, ou essencial, à população naquele momento, evidente a partir da vinculação constitucional à destinação mínima de receitas como a saúde (art. 198, §§2º e 3º) e a educação (art. 212), por exemplos.

Por consequência, parece estar mesmo a cargo do Poder Judiciário deliberar sobre a efetividade do direito à saúde, diante da omissão do Poder Legislativo e da ineficiência de gestão do Poder Executivo, determinando o cumprimento desse direito indispensável à manutenção da vida.

\section{DECISÕES DO SUPREMO TRIBUNAL FEDERAL}

O direito à saúde não atinge níveis satisfatórios no Brasil, o país encontra sérias dificuldades para efetivá-lo com justificativas de falta de recursos financeiros. ${ }^{8}$ Nesse sentido, o Estado passou a invocar a teoria da reserva do possível para fundamentar a impossibilidade de promover direitos sociais em razão da escassez orçamentária, tentando vincular tais direitos a critérios de razoabilidade e ponderação orçamentária. ${ }^{9}$

Outro argumento é a afronta ao princípio do pacto federativo determinante da separação dos poderes; haveria interferência inconstitucional no poder discricionário da Administração Pública, pois é de sua competência elaborar a lista de medicamentos a serem fornecidos à população. Quando o Poder Judiciário determina o fornecimento de algum medicamento, por exemplo, que não conste desse rol, haveria ofensa ao princípio da separação dos poderes. 0 mesmo ocorreria caso fosse determinado o bloqueio de contas públicas para o custeio de tratamentos médico-hospitalares e arbitrada multa diária no caso de não cumprimento das obrigações determinadas por decisão judicial. ${ }^{10}$

Embora existam inúmeras críticas em razão do ativismo judicial, parece ser justo e legítimo que os tribunais concedam medidas (tratamento médico-hospitalar, tais como medicamentos, cirurgias, internações etc.) visando à tutela do direito à saúde, frente às omissões legislativas e à ingerência Estatal - o cidadão não pode ser penalizado por erros de administração e má aplicação de recursos públicos, especialmente em se tratando de saúde, pois seria pagar com a própria vida. 
Mas os problemas dos direitos fundamentais não são somente a falta de recurso e a má Administração Pública que demandam o ativismo do Judiciário para sua realização. Conforme Antônio Carlos de Araújo Cintra, Ada Pellegrini Grinover e Cândido Rangel Dinamarco (2006, p. 172), quando os direitos fundamentais são violados ou colocados em dúvida em razão de normas constitucionais vagas e genéricas, "só podem ser firmados, positivamente e efetivados pelos tribunais", pois é pelo Poder Judiciário que se opera a correção "da imperfeita realização automática do direito".

De acordo com os princípios estabelecidos no art. 7ํㅡ da Lei $\mathrm{n}$. 8.080/90, a assistência à saúde deve ser universal e integral, contemplando desde o plano individual até o coletivo, em qualquer grau de complexidade do procedimento/tratamento a ser realizado como corolário ao direito à vida e à dignidade humana.

As decisões do STF (Supremo Tribunal Federal), com relação à aplicação da teoria da reserva do possível para afastar as prestações advindas do direito à saúde, têm se firmado no sentido de se garantir o mínimo existencial.

Conforme o voto do Ministro Celso de Mello no Agravo Regimental no Recurso Extraordinário n. 639337/SP (STF, 2011):

A cláusula da reserva do possível - que não pode ser invocada, pelo Poder Público, com o propósito de fraudar, de frustrar e de inviabilizar a implementação de políticas públicas definidas na própria Constituição - encontra insuperável limitação na garantia constitucional do mínimo existencial, que representa, no contexto de nosso ordenamento positivo, emanação direta do postulado da essencial dignidade da pessoa humana. [...] A noção de 'mínimo existencial', que resulta, por implicitude, de determinados precei-

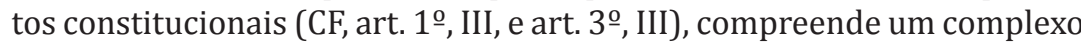
de prerrogativas cuja concretização revela-se capaz de garantir condições adequadas de existência digna, em ordem a assegurar, à pessoa, acesso efetivo ao direito geral de liberdade e, também, a prestações positivas originárias do Estado, viabilizadoras da plena fruição de direitos sociais básicos, tais como o direito à educação, o direito à proteção integral da criança e do adolescente, o direito à saúde, o direito à assistência social, $\mathrm{o}$ direito à moradia, o direito à alimentação e o direito à segurança. Declaração Universal dos Direitos da Pessoa Humana, de 1948 (Artigo XXV).

O Supremo Tribunal Federal tem consolidado entendimento "no 
sentido de que, apesar do caráter meramente programático atribuído ao art. 196 da Constituição Federal, o Estado não pode se eximir do dever de propiciar os meios necessários ao gozo do direito à saúde dos cidadãos" [STF. Recurso Extraordinário n. 775.133/SP, Ministro Roberto Barroso, data de julgamento: 07/02/2014].

Inclusive não se podem vincular as prestações de saúde, exclusivamente, a casos extremados, ou seja, "vincular o direito à saúde apenas às situações em que se verifica grave e iminente risco de morte", pois as disposições constitucionais relativas à implementação de políticas públicas voltadas à saúde abrangem todos os meios necessários para a redução do risco de doenças. "Portanto, além de efetivar medidas voltadas à correção de distúrbios já constatados, é imperativa também a adoção de métodos destinados à prevenção de eventuais enfermidades e à manutenção das políticas previamente estabelecidas" [STF. Recurso Extraordinário n. 775.133/SP, Ministro Roberto Barroso, data de julgamento: 07/02/2014].

Percebe-se que, sendo o objeto da demanda social a saúde, o STF tem dado provimento às pretensões de fornecimento de medicamentos, internação e realização de procedimentos ambulatoriais e cirúrgicos necessários para preservação da vida e, com isso, está garantindo a dignidade humana.

Embora os impactos orçamentários provenientes de uma decisão judicial não possam ser desconsiderados, na maioria das vezes, pela análise das decisões, verificou-se a falta de vontade política e a má gestão pública na melhoria dos serviços de saúde públicos e não na ausência e/ou escassez de recursos. Não nos parece justo que a Administração Pública não forneça serviços de saúde à população e se "esconda" no manto protetivo da "escassez", uma vez que não administra corretamente e, muito menos, satisfatoriamente o dinheiro público.

Nesse sentido, imprescindível a atuação do STF [Agravo Regimental no Recurso Extraordinário n. 410.715/SP, data de julgamento: 03/11/2015] na defesa e aplicabilidade das determinações constitucionais; afinal, é ele o seu "guardião".

Embora resida, primariamente, nos Poderes Legislativo e Executivo, a prerrogativa de formular e executar políticas públicas, revela-se possível, 
no entanto, ao Poder Judiciário, determinar, ainda que em bases excepcionais, especialmente nas hipóteses de políticas públicas definidas pela própria Constituição, sejam estas implementadas pelos órgãos estatais inadimplentes, cuja omissão - por importar em descumprimento dos encargos político-jurídicos que sobre eles incidem em caráter mandatório mostra-se apta a comprometer a eficácia e a integridade de direitos sociais e culturais impregnados de estatura constitucional. A questão pertinente à "reserva do possível".

Ao apreciar o Recurso Extraordinário n. 592.581, o Supremo Tribunal Federal, por unanimidade, afastou a aplicação da teoria da reserva do possível, responsabilizando o Poder Executivo pela efetivação dos preceitos Constitucionais, no sentido de melhorias em presídios para efetivação da dignidade da pessoa humana e da tutela da integridade psicofísica dos presos. Nas palavras do Relator, Ministro Ricardo Lewandowski [STF. Recurso Extraordinário n. 592.581/RS, data de julgamento: 13/08/2017],

A reserva do possível não pode servir de argumento para escusar o Estado de cumprir os comandos constitucionais, sobretudo aqueles expressamente nomeados e caracterizados como direitos fundamentais. Eventual objeção orçamentária deveria ser acompanhada de prova expressa, documental, que justifique adequadamente e demonstre a impossibilidade financeira do Estado, bem como porque as escolhas político-governamentais deixaram de atender demanda tão fundamental. A invocação da reserva do possível não pode consistir em mera alegação que isenta, por si só, o Estado de suas obrigações. Somente justo motivo, objetivamente aferido, tem tal valia. [...] é lícito ao Judiciário impor à Administração Pública obrigação de fazer, consistente na promoção de medidas ou na execução de obras emergenciais em estabelecimentos prisionais para dar efetividade ao postulado da dignidade da pessoa humana e assegurar aos detentos o respeito à sua integridade física e moral, nos termos do que preceitua o art. 5ํㅡ, XLIX, da Constituição Federal, não sendo oponível à decisão o argumento da reserva do possível nem o princípio da separação dos poderes (STF. RE. 592.581/ RS. Plenário. Data de julgamento: 13/08/2015).

Mais uma vez, verifica-se a interpretação sistêmica e finalística dos dispositivos e princípios constitucionais para proteção aos direitos fundamentais, buscando-se aplicabilidade desses direitos inerentes à própria condição humana para o exercício de uma vida com o mínimo 
de dignidade, defendida pela teoria do mínimo existencial.

Afastar a teoria da reserva do possível para concretização dos direitos fundamentais é conferir aos cidadãos os direitos preconizados pela Lei Maior, os quais devem ser pensados no momento da elaboração orçamentária da Administração Pública como prioridades, deixando o plano hipotético para o da concretização.

E para isso, mister analisar alguns métodos de interpretação e aplicação das normas constitucionais. Para este estudo, o princípio da proporcionalidade e o da cedência recíproca (ou da harmonização ou da concordância prática).

O princípio da proporcionalidade orienta o intérprete na "busca da justa medida de cada instituto jurídico", com vistas à "ponderação entre os meios utilizados e os fins perseguidos", privilegiando a interpretação que menos importar "sacrifício ao cidadão ao escolher dentre os vários possíveis significados da norma." (ARAUJO; NUNES JUNIOR, 2015, p. 128). Trata-se da aplicação principiológica de otimização das possibilidades fáticas e jurídicas ${ }^{11}$ analisando-se o caso concreto. Otimizar implica relativização das possibilidades jurídicas de um determinado princípio, em razão do peso do princípio colidente analisando-se o caso concreto, sendo imprescindível um exercício de ponderação axiológica ${ }^{12}$ na busca por uma "função útil a cada um dos direitos em confronto", sem que a aplicação de um importe em supressão do outro, encontrando-se um ponto de convivência entre eles, mais uma vez, por meio da ponderação desses valores conflitantes (ARAUJO; NUNES JÚNIOR, 2015, p. 125).

Nesse sentido, o juízo de sopesamento nada mais é que a teoria da proporcionalidade, assuntos relevantes a esta pesquisa por estarem umbilicalmente ligados à aplicação das teorias do mínimo existencial e da reserva do possível.

A aplicação do princípio da proporcionalidade assume três importantes vertentes: o trinômio adequação, necessidade e proporcionalidade em sentido estrito.

Verificar a adequação e a necessidade é analisar se a medida adotada promoverá a finalidade legítima a que se destina e se existem outras medidas, menos gravosas e eficazes tanto quanto àquela capazes de resolver o problema. "Em outros termos, essas duas sub-regras concernem à ideia de 
otimização no que atina às possibilidades fáticas - dimensão empírica da proporcionalidade". Já a proporcionalidade em sentido estrito, "diz respeito à otimização no tocante às possibilidades jurídicas - dimensão normativa da proporcionalidade" (ALEXY, 2005, p. 573 apud LUCREDI, 2014, p. 171).

Atualmente, o Supremo Tribunal Federal vem prolatando decisões lastreadas em juízos de sopesamento com vistas à efetividade da dignidade humana e da tutela à vida, aqui inserto o direito à saúde. Sob essa perspectiva, o Supremo tem afastado a aplicação da teoria da reserva do possível e concedido a tutela jurisdicional para efetivação desse direito fundamental social.

Fato gerador de muita discussão e severas críticas pelos adeptos da teoria da reserva do possível, com fundamentos no comprometimento da segurança nacional, na afronta direta ao princípio da separação dos Poderes e danos à economia nacional, facultando "ampla discricionariedade ao Judiciário ao interpretar princípios, ensejando o espanto dos investidores que naturalmente procuram estabilidade no atendimento de suas expectativas", uma vez que "o modelo adjudicatório ponderativo não estipula limites à jurisdição constitucional, podendo ela em nome dos direitos reformar ou anular qualquer medida legislativa ou política social que lhe pareça infensa à constituição." (LUCREDI, 2014, p. 163-164).

No entanto, como observam Virgílio Afonso da Silva e Fernanda Vargas Terrazas, citados por Gustavo Lucredi (2014, p. 165-166), inúmeras decisões do Supremo envolvendo a ineficiência de recursos destinados à saúde "albergam interpretações iníquas do ponto de vista macrossocial dos direitos fundamentais, porém, aparentemente justas do ponto de vista individual."

No afã de se promover a justicialidade dos direitos sociais, acabou-se, na verdade, agravando-se um quadro de desigualdade social, uma vez que a intervenção dos órgãos jurisdicionais nessa área revelou-se, afinal, um agente concentrador de renda, já que os mais beneficiados não são os mais pobres, mas, sim a camada intermediária da população. (grifo nosso)

Sob tal prisma, questiona-se o agravamento da crise social, isto é, aumento na desigualdade social em razão da judicialização dos direitos 
sociais, em virtude da população carente não ser a mais beneficiada com o ativismo judicial.

A proposta de Lucredi (2014, p. 167-168) é demonstrar a possibilidade de aplicação da teoria de otimização (lei de sopesamento, ou lei de ponderação) de Robert Alexy, atingindo-se ótimos níveis de satisfação dos direitos fundamentais, inclusive por meio de decisões judiciais, mas, da mesma forma, promovendo-se o desenvolvimento econômico e social da nação, sem prejudicar as atribuições dos Poderes da República, permitindo-se uma alocação de recursos financeiros eficiente, em consonância com as instituições democráticas, sem usurpação de funções governamentais ou intervenções estatais nocivas ao domínio econômico.

Os princípios podem ser efetivados em diferentes graus, pois sua execução independe exclusivamente de circunstancias fáticas envoltas no caso concreto, mas também, na mesma intensidade, das possibilidades jurídicas colidentes - o apregoado pela reserva do possível.

"Percebe-se de forma clarividente uma preponderância dos sistemas político e financeiro em detrimento do sistema jurídico, haja vista que a concretização dos direitos fundamentais encontra-se na dependência da vontade política e da previsão orçamentária." (CARVALHO; LIMA, 2015, p. 215). Inquestionável tal fato, como também não se pode negar que as influências externas ("não jurídicas"13) modificam e, até mesmo, se tornam barreiras à aplicação do direito, mas tratando-se de direitos fundamentais não se pode admitir sua ineficácia, ou melhor, a impossibilidade de efetivá-los em virtude de influências externas, pois estaríamos privando o ser humano de condições básicas do exercício digno do direito à vida.

O sopesamento busca identificar qual dos interesses tem maior peso no caso concreto, priorizando um princípio em detrimento de outro.

[...] toda alocação de direitos que estiver situada nas extremidades ou no interior da fronteira de satisfação não merece a intervenção do Judiciário. Sintomaticamente, a fronteira de satisfação serve como um indicador ao Judiciário de que, conquanto haja uma alternativa mais vantajosa em termos de distribuição e restrição de direitos fundamentais, existe uma grande margem dentro da qual deverá prestar deferência à Administração Pública ou ao Legislativo, em prol do respeito aos chamados princípios formais. Isso porque nesse panorama de direitos relativizados pelas contingências 
materiais, surge a delicada questão das escolhas trágicas, as quais competem, por excelência, à esfera política (LUCREDI, 2014, p. 185).

"A ponderação sustentava-se na perspectiva da racionalidade do 'princípio da proporcionalidade' (ponderação relativa) e na sacralidade substantiva do princípio vetor da dignidade da pessoa humana (ponderação absoluta) " (CRUZ, 2004, p. 195).

Álvaro Ricardo de Souza Cruz (2004, p. 195) sintetiza as principais críticas às formas de ponderação:

a) desnaturação do princípio da separação dos poderes;

b) limitação da supremacia constitucional, pela "transformação dos Tribunais Constitutionais em Assembléias [sic] Constituintes;

c) desnaturação dos direitos fundamentais e da unidade normativa da Constituição;

d) politização do Judiciário, por meio de decisões unilaterais de custo/ benefício sociais;

e) a decisão tornara-se campo para arbítrio puro, de preferências pessoais dos juízes;

f) irracionalidade metodológica.

Nesse contexto, de mudanças de concepção, de superação das contradições do positivismo jurídico com vistas à maior efetividade de valores humanos e dos princípios constitucionais, surge a chamada jurisprudência dos valores ou jurisprudência dos princípios.

A Jurisprudência de Valores ou Wertjurisprudenz, como é denominada pela doutrina alemã, é defendida pelas Cortes europeias, as quais adotam a dignidade da pessoa humana como metavalor, sobre a qual nenhuma ponderação poderá violá-la. Tal valor, da dignidade humana, "seria um norte segura para que as decisões judiciais fossem sempre racionais e ao mesmo tempo consentâneas com os valores mais caros à humanidade" (CARVALHO; LIMA, 2015, p. 232). A jurisprudência de valores é uma construção com alto grau de abstração, pela simples razão de ser aplicada à totalidade do ordenamento jurídico (GARCÍA, 1984, p. 278).

Segundo Álvaro Ricardo de Souza Cruz (2004, p. 263), com a aplicação da Jurisprudência de Valores a Corte Constitucional 
[...] torna-se um poder absoluto, um poder ilimitado, que se permite "brincar" com a "supremacia da Constituição" abandonando a linguagem em favor de um poder desmedido. A "Jurisprudência dos Valores" é um engodo do poder burocrático, que coloniza o mundo devia, atraindo a seu favor, tal qual faziam as sereias com os marinheiros desprevenidos, as Cortes Constitucionais.

Infere-se, a partir de uma Constituição, a existência de uma ordem de valores concreta, havendo concorrência/colidência entre o Direito e os valores, ou seja, entre o obrigatório e o negociável, pela teoria da jurisprudência dos valores, haverá ponderação material de valores no sentido da aplicação daquele que mais privilegie os preceitos do Estado Democrático de Direito, o princípio matriz de todo o sistema jurídico: a dignidade da pessoa humana.

Os críticos a essa teoria afirmam se tratar de privilégio ao arbítrio na aplicação do direito, aumentando o espectro da atuação discricionária dos magistrados, em detrimento da discricionariedade da Administração Pública, por exemplo.

Luis Recaséns Sisches (1998, p. 60), com uma visão positivista, afirma que a valorização dos interesses realizada pelo legislador deve prevalecer sobre a valorização individual que o juiz poderia fazer de acordo com seus critérios pessoais.

Continua o autor (Op. cit., p. 62), o juiz deve proteger todos os interesses que o legislador considerou dignos de proteção, e em grau e hierárquia em que ele os tenha estimado para serem protegidos, definido como processo de analogia pela literalidade da lei.

Entretanto, Jorge Olvera García e Reynaldo Robles Cardoso (2016, p. 67) reconhecem o homem como o centro do direito e a necessidade de se compatibilizarem os princípios contidos nos direitos humanos para se alcançar a justiça:

O homem é a origem e propósito do Estado, é a figura fundamental da organização, por ele se criou o Estado e para ele se criou o respeito, a proteção, a eficácia dos direitos humanos, é o principal objetivo do Estado, de sua atividade; nos direitos humanos encontramos os fins e valores que determinam e definem a atividade Estatal, o princípio pro homine [diante de um conflito de normas deverá ser assegurada aquela que mais amplia 
os direitos e garantias fundamentais da pessoa humana] obriga qualquer autoridade para privilegiar os direitos do homem. Entendemos que se privilegia o homem, que deve ter prevalência a qualquer outra finalidade como é a de obter maiores recursos, que dentro das finanças é um objetivo louvável, mas deve conciliar e priorizar os princípios contidos nos direitos humanos que protegem privilegiando homem: a equidade, a proporcionalidade e a legalidade, os quais contribuem para alcançar a justiça, valor muito apreciado pelo ser humano.

(Tradução livre)

Percebe-se, pelo exposto acima, que a jurisprudência dos valores, pressupondo ser a constituição uma ordem concreta de valores, faz uma confusão entre Direito (aquilo que é devido, obrigatório ou permitido) e valores (aquilo que é negociável e passível de preferências), negando, então, o caráter obrigatório do Direito. Além do mais, prescinde da limitação de espectro argumentativo imposta pela distinção entre os discursos de aplicação e justificação.

Nesse sentido, os argumentos da tutela do mínimo existencial convergem aos interesses da tutela humana, garantindo-se a todo cidadão o direito à saúde como corolário do direito à vida e a efetividade do princípio da dignidade humana.

Segundo Jorge Oliveira García e Reynaldo Robles Cardoso (2016, p. 73), valores são anseios, aspirações, objetivos, que não são suscetíveis de se atingir; no entanto, o homem os estabelece como parâmetro que lhe permite medir suas ações, em direção ou para longe do objetivo almejado.

A perspectiva humanista entende por valor aquele que tem como destinatário um homem, sem ele perderia sua humanidade ou parte dela. O valor seria uma "excelência inatingível". Os maiores pontos de vista para a orientação da vida, dando-lhe sentido, são os valores. A realização de valores somente será possível se obtida uma utilidade, um fim, os valores são fins em si mesmos, tanto ao homem como à coletividade (GARCÍA; CARDOSO, 2016, p. 73-74).

Fato é que a vinculação orçamentária não permite a prestação de todos os direitos garantidos pela Constituição Federal, mas tal argumento não justifica o "abandono" dos direitos fundamentais e, bem por isso, o "gestor público - no momento da elaboração das políticas públicas - 
deverá realizar a alocação de recursos financeiros de modo a garantir a maior aplicação de um direito em detrimento de outros", analisando-se quais são os direitos fundamentais que receberam a maior parcela orçamentária para o atendimento das necessidades básicas e vitais da população (CARVALHO; LIMA, 2015, p. 217).

A Constituição é a Lei Maior, contém regras básicas e fundamentais, nela se estabelecem os princípios que regem a organização e a atividade governamental. Os objetivos da sociedade se refletem essencialmente nos direitos humanos, os quais expressam os valores que o povo privilegia: vida, dignidade, liberdade, igualdade, segurança jurídica, dentre outros (GARCÍA; CARDOSO, 2016, p. 75), os quais constituem um rol de direitos essenciais à subsistência humana, o mínimo para uma existência digna, e, por tal razão, devem ser privilegiados em detrimento de outros, pela teoria da ponderação, de gradação inferior em virtude de sua posição secundária.

Logo, as decisões do Supremo na efetivação do direito à saúde guardam total consonância com o texto constitucional e atendem às necessidades sociais, as quais parecem, salvo melhor juízo, não serem prioridades da Administração Pública. "É possível ao Poder Judiciário determinar a implementação pelo Estado, quando inadimplente, de políticas públicas constitucionalmente previstas, sem que haja ingerência em questão que envolve o poder discricionário do Poder Executivo" [STF. Agravo Regimental no Agravo de Instrumento n. 734.487/PR, data de julgamento: 03/08/2010].

Pois bem, no caso de omissão governamental e legislativa envolvendo fatores como a má gestão de recursos, desvios de verbas públicas, ausência ou insuficiência de políticas públicas e de investimentos na saúde, um direito fundamental social de todo cidadão, incumbe ao STF atuar positivamente, garantindo o mínimo necessário à manutenção de uma vida digna. Ato também de controle entre os Poderes, previsto no sistema de checks and balances aplicado no pacto federativo.

\section{CONCLUSÃO}

A teoria da reserva do possível tem sido utilizada para justificar a não concretização de direitos fundamentais sociais pelo Estado, sob 
argumentos da discricionariedade do Poder Executivo na aplicação de recursos orçamentários, proveniente da Separação dos Poderes e, também, na impossibilidade de garantir efetividade a todos os direitos fundamentais consagrados pela Constituição Federal.

Sem dúvidas, os direitos e as liberdades fundamentais precisam de recursos financeiros para serem concretizados. Por isso, para contrapor a teoria da reserva do possível na garantia de um núcleo mínimo essencial à própria subsistência do homem, nasce a teoria do mínimo existencial, teoria adotada pelo Supremo Tribunal Federal quando o assunto é saúde, a partir de juízos de sopesamento com vistas à tutela da vida e dignidade humana.

Esse juízo de sopesamento é lastreado com base na aplicação do princípio da proporcionalidade, o qual requer a utilização do trinômio adequação, necessidade e proporcionalidade em sentido estrito.

A análise da adequação e da necessidade demonstrará se a medida adotada atingirá uma finalidade legítima e se existem outras medidas menos gravosas e tão ou mais eficazes na resolução do caso e para efetividade dos direitos fundamentais, enquanto a proporcionalidade em sentido estrito atinge a dimensão normativa propriamente dita, direcionando pela ponderação relativa (essa racionalidade do princípio da proporcionalidade) e pela ponderação absoluta (aplicação do princípio vetor da dignidade da pessoa humana) qual norma será aplicada em detrimento da outra, coadunando-se a observância do princípio da cedência recíproca.

O gestor público, ao elaborar as políticas públicas, deverá alocar recursos suficientes à efetividade dos direitos fundamentais para o atendimento das necessidades vitais da população, garantindo o mínimo existencial para uma vida digna.

Incumbe ao Estado a tutela dos bens necessários à sobrevivência dos indivíduos em razão da acentuada desigualdade social no país. 0 amparo social estatal com vistas ao fornecimento de condições dignas de vida (saúde, educação, alimentação, habitação, transporte etc.) é uma responsabilidade erigida constitucionalmente. Trata-se do mínimo existencial, sem o qual não se garante o direito à vida e à dignidade humana e, por consequência, não se pode falar em justiça social, redistribuição 
igualitária de renda, redução das desigualdades sociais e erradicação da pobreza, estando o país cada vez mais distante de se constituir em uma sociedade livre, justa e solidária.

0 direito à saúde é um desdobramento do direito à vida, são indissociáveis; o direito à vida somente será garantido em sua plenitude se houver saúde e dignidade. 0 Estado precisa buscar meios para solucionar os problemas que impedem a efetividade dos direitos sociais. Imprescindível o desenvolvimento de políticas públicas mais eficazes, aumento nos investimentos tecnológicos (aparelhos e informatização do sistema), capacitação profissional e de estrutura física das unidades de saúde e dos hospitais públicos.

Diante da omissão do Poder Legislativo e da ineficiência do Poder Executivo na questão da saúde, o Poder Judiciário tem atuado no sentido de garantir o mínimo existencial ao cidadão, compelindo a Administração Pública ao cumprimento das prestações de saúde por meio de ações individuais, cuja maioria versa sobre o fornecimento de medicamentos, vagas em hospitais, autorização de exames e procedimentos cirúrgicos pela rede pública.

Embora os impactos econômicos gerados pelas decisões judiciais não possam ser desconsiderados, não há de se falar em afronta aos princípios do pacto federativo e da separação de poderes, uma vez que a própria Constituição Federal prevê mecanismos para a efetivação dos direitos fundamentais em caso de omissão do Legislativo e da revisão (e até anulação) dos atos que extrapolem o poder discricionário da Administração Pública e/ou no caso de sua má gestão da res pública.

Em que pese o fato da justiciabilidade dos direitos sociais agravar o quadro de desigualdade social, em razão da falta/dificuldade da classe financeiramente carente da população (camada baixa) no acesso ao Judiciário e os maiores beneficiados serem pessoas pertencentes a classe intermediária, o ativismo judicial não pode ser visto como o único vilão, principalmente quanto ao agravamento de crises, pois o Legislativo e o Executivo têm tanta responsabilidade quanto o Judiciário, se considerarmos todo o contexto de décadas de inexperiência e ineficiência em suas respectivas atividades, funções típicas e competências conferidas pela Carta Republicana de 1988. 
Em síntese, o Legislativo, ao elaborar leis, muitas vezes inaplicáveis e que não atingem os interesses dos menos favorecidos, inclusive aprovando orçamentos impossíveis de serem cumpridos, e o Executivo pela ingerência de suas políticas públicas e destinação, muitas vezes, inadequadas dos recursos financeiros.

Nesse sentido, os argumentos da tutela do mínimo existencial devem ser adotados em detrimento da reserva do possível quando o assunto é "saúde", garantindo-se a todo cidadão indistintamente esse direito como corolário do direito à vida e a efetividade do princípio da dignidade humana.

\section{NOTAS}

1 Segundo Holmes e Sustein (1999, p. 15; 97), "os direitos não podem ser protegidos ou exercidos sem o financiamento e o sustento público. [...] Tanto os direitos sociais quanto o direito à propriedade privada têm custos públicos. 0 direito à liberdade de contratar tem custos públicos não menos que o direito à saúde, o direito à liberdade de expressão não menos que o direito à moradia digna. [...] Nada que custa dinheiro pode ser absoluto" (tradução nossa).

2 A linha de extrema pobreza é definida a partir de uma estimativa do valor de uma cesta de alimentos com o mínimo de calorias necessárias para suprir satisfatoriamente uma pessoa, seguindo-se a recomendação da FAO (Organização das Nações Unidas para Alimentação e Agricultura) e OMS (Organização Mundial da Saúde). O IPEA disponibiliza uma tabela com as linhas de extrema pobreza estimadas para cada região do país. A título informativo, na área urbana do Estado de São Paulo em 2013, o valor apurado é de R $\$ 125,35$. Porto Alegre (área metropolitana) apresenta o maior nível, $\mathrm{R} \$ 156,91$ enquanto o menor, $\mathrm{R} \$ 84,42$ fica com a região Leste do país (área rural). A tabela poderá ser consultada na íntegra no site do IPEA, no link: <http://www. ipeadata.gov.br/>.

3 Última pesquisa divulgada e atualizada pelo IPEA: 07/01/2016.

4 A última atualização desses dados pelo IPEA foi no ano de 2015.

5 A origem dos direitos fundamentais remota às antigas civilizações, como o Egito e a Mesopotâmia, nas quais já se identificavam alguns instrumentos protetivos dos indivíduos perante o Estado. Alexandre de Moraes (2007, p. 6) discorre sobre o assunto e cita o Código de Hammurabi como exemplo: "A origem dos direitos individuais do homem pode ser apontada no antigo Egito e Mesopotâmia, no terceiro milênio a.C., onde já eram previstos alguns mecanismos para proteção individual em relação ao Estado. 0 Código de Hammurabi (1960 a.C.) talvez seja a primeira codificação a consagrar um rol de direitos comuns a todos os homens, tais como a vida, a propriedade, a honra, a dignidade, a família, prevendo, igualmente, a supremacia das leis em relação aos governantes."

6 "A crise econômica que teve início em 2008 e culminou com a quebra do banco Lehman Brothers nos EUA refletiu no mundo inteiro, incluindo o Brasil, fazendo com que o governo apostasse na redução do esforço fiscal e no aumento dos gastos públicos como medida de estímulo. [...] Com a desaceleração da economia diante das intempéries internacionais, o governo passou a adotar uma política anticíclica, que consistia em aumentar os gastos para impulsionar a economia. [...] No entanto, o que foi considerado como uma medida de estímulo no passado se transformou, hoje, em um dos grandes desafios do governo: cortar despesas. [Além disso] Ao tornar o crédito e o investimento mais caros, os juros elevados acabam prejudicando o crescimento da economia." 
(CURY; CAVALLINI, 2015). Além disso, o Brasil passa por uma crise política, questiona-se a própria democracia; há falta de credibilidade do governo e de sua equipe econômica; apontam-se a má gestão e os sucessivos escândalos de corrupção envolvendo políticos, empresários e o governo federal como fatores contributivos à recessão.

70 mínimo existencial também recebe outras denominações: mínimo vital, mínimo material, limiar mínimo, piso vital, mínimo indispensável, dentre outros.

8 "Há consenso, entre os que se dedicam a analisar a questão da saúde no Brasil, de que o SUS sofre uma insuficiência crônica de recursos financeiros. A participação dos recursos públicos no gasto total com saúde, menos de $50 \%$ do total, não resiste a uma comparação com países que também possuem sistemas públicos com responsabilidade de cobertura universal. Nesses países, a participação pública nunca é inferior a 70\% do total. Aportar maior volume de recursos para o SUS é condição essencial para que o sistema público possa cumprir suas responsabilidades constitucionais." (IPEA, 2015, p. 171).

9 Conforme argumentação da Administração Pública no Agravo Regimental no Recurso Extraordinário n. 639337/SP, data de julgamento: 23/08/2011; no Recurso Extraordinário n. 775.133/SP, data de julgamento: 07/02/2014; no Agravo Regimental no Recurso Extraordinário n. 410.715/SP, data de julgamento: 03/11/2015; no Recurso Extraordinário n. 592.581/RS, data de julgamento: $13 / 08 / 2015$.

10 Id. Ibid.

11 Em síntese, princípios são mandamentos de otimização, instrumentos que determinam a realização de atos na maior intensidade possível dentro das possibilidades jurídicas e fáticas. Os princípios representam razões indicativas de uma direção, são comandos que direcionam decisões (ALEXY, 2002b, p. 99).

12 Que Robert Alexy nomeou lei de ponderação, propondo a utilizar a ponderação como via para otimização do ordenamento jurídico, cuja premissa é a aplicação da unidade da Constituição (entendê-la como um todo, de modo global, interpretando-a em sua completude para justamente se prevenir antinomias).

13 Marcelo Neves (apud CARVALHO; LIMA, 2015, p. 215) exemplifica como pressupostos não jurídicos os econômicos, os políticos, os culturais e os técnicos; tratam-se de influências externas, não jurídicas, mas que "gera a modulação da sua forma de atuação".

14 “[... valoración de los intereses llevada a cabo por el legislador debe prevalecer sobre la valoración individual que el juez pudiera hacer según su personal criterio.” (SISCHES, 1998, p. 60).

\title{
REFERÊNCIAS
}

ALEXY, Robert. Epílogo a la teoria de los derechos fundamentales. Revista Española de Derecho Constitucional, Madrid, ano 22, n. 66, p. 13-64, set./dez. 2002a.

. Teoría de los derechos fundamentales. Tradução de Ernesto Garzón Valdés. Madrid: Centro de Estudios Políticos y Constitucionales, 2002b.

\author{
ARAUJO, Luiz Alberto David; NUNES JUNIOR, Vidal Serrano. Curso de direito \\ constitucional. 19. ed. São Paulo: Verbatim, 2015.
}

BOBBIO, Norberto. A era dos direitos. Tradução de Carlos Nelson Coutinho. Rio de Janeiro: Campus, 1998. 
BONAVIDES, Paulo. Curso de direitos constitucional. 25. ed. São Paulo: Malheiros, 2010.

BRASIL. Constituição da República Federativa do Brasil de 1988. Disponível em: <http://www.planalto.gov.br/ccivil_03/constituicao/constitui\%C3\%A7ao. htm>. Acesso em: 19 jun. 2017.

Lei n. 8.080, de 19 de setembro de 1990. Dispõe sobre as condições para a promoção, proteção e recuperação da saúde, a organização e o funcionamento dos serviços correspondentes e dá outras providências. Disponível em: <http:// www.planalto.gov.br/ccivil_03/leis/L8080.htm>. Acesso em: 20 jun. 2017.

Supremo Tribunal Federal (Plenário). Recurso Extraordinário n. 592.581/RS. Data de julgamento: 13 de agosto de 2017. Disponível em: <http:// redir.stf.jus.br/paginadorpub/paginador.jsp?docTP=TP\&docID=10166964>. Acesso em: 30 maio 2017.

. Supremo Tribunal Federal (1. Turma). Recurso Extraordinário n. 775.133/SP. Ministro Roberto Barroso. Data de julgamento: 07/02/2014. Disponível em: <http://www.stf.jus.br/portal/processo/verProcessoAndamento. asp?incidente $=4472444>$. Acesso em: 24 jun. 2017.

(2. Turma). Agravo Regimental no Recurso Extraordinário n. 639337/SP. Relator: Ministro Celso de Mello. Data de julgamento em: 23/08/2011. Disponível em: <http://webcache.googleusercontent.com/ search?q=cache:210jXIirGu0J:www.stf.jus.br/portal/jurisprudencia/visualizarEmenta.asp\%3Fs1\%3D000179240\%26base\%3DbaseAcordaos $+\& \mathrm{~cd}=1 \& \mathrm{hl}=$ pt-BR\&ct=clnk\&gl=br>. Acesso em: 24 jun. 2017.

Agravo Regimental no Recurso Extraordinário n. 410.715/SP. Relator: Ministro Celso de Mello. Data de julgamento em: 03 nov. 2015. Disponível em: <http://www.stf.jus.br/portal/jurisprudencia/pesquisarJurisprudencia.asp>. Acesso em: 24 jun. 2016.

Agravo Regimental no Agravo de Instrumento n. 734.487/PR. Relatora: Ministra Ellen Gracie. Data de julgamento: 03/08/2010. Disponível em: <http://www.stf.jus.br/portal/jurisprudencia/pesquisarJurisprudencia.asp>. Acesso em: 24 jun. 2017. 
CARVALHO, Pedro de Menezes; LIMA, Renata Dayanne Peixoto de. Orçamento público e direito fundamental: a limitação orçamentária à implementação dos direitos fundamentais. Cientefico, Fortaleza, v. 15, n. 32, p. 195-220, jul./dez. 2015.

CHADE, Jamil. Brasil terá maior alta do desemprego entre grandes economias em 2016, prevê OIT. Estadão, 19 jan. 2016. Disponível em: <http://economia. estadao.com.

br/noticias/geral,brasil-tera-maior-alto-do-desemprego-entre-grandes-economias-em-2016--preve-oit,10000007484> . Acesso em: 23 jun. 2017.

CINTRA, Antônio Carlos de Araúlo; GRINOVER, Ada Pellegrini; DINAMARCO, Cândido Rangel. Teoria geral do processo. 22. ed. São Paulo: Malheiros, 2006.

COSTA, Tailson Pires. Dignidade da pessoa humana diante da sanção penal. São Paulo: Fiuza Editores, 2004.

CRUZ, Álvaro Ricardo de Souza. Jurisdição constitucional democrática. Belo Horizonte: Del Rey, 2004.

CURY, Anay; CAVALLINI, Marta. Conheça cinco causas do 'fôlego curto' da economia brasileira. In: G1: Economia, 27 mar. 2015, atual. 28 mar. 2015. Disponível em: <http://g1.globo.com/economia/noticia/2015/03/conheca-cinco-causasdo-folego-curto-da-economia-brasileira.html>. Acesso em: 23 jun. 2017.

GARCÍA, Enrique Alonso. La interpretación de la constitución. Madrid: Centro de Estudios Constitucionales, 1984.

GARCÍA, Jorge Olvera; CARDOSO, Reynaldo Robles. Los principios constitucionales en materia financiera. In: SEDEÑO, Joaquín Ordóñez; ARZATE, Enrique Uribe (Coords.). Problemas constitucionales del México contemporáneo. México: Universidad Autónoma del Estado do México, 2016.

HOLMES, Stephen; SUSTEIN, Cass. The Cost of rights: why liberty depends on taxes. New York: W. W. Norton and Company, 1999.

LUCREDI, Gustavo. Princípios como um fator de direito e desenvolvimento: uma visão jurídico-econômica da tutela judicial de direitos fundamentais. Revista Jurídica da Procuradoria Geral do Estado do Paraná, Curitiba, n. 5, p. 163$192,2014$. 
INSTITUTO BRASILEIRO DE GEOGRAFIA E ESTATÍSTICA (IBGE). Taxa de desemprego. Atualizado em: 17/11/2015. IPEADATA: Social: dados e indicadores sobre distribuição de renda, pobreza, educação, saúde, previdência social e segurança pública. Disponível em: <http://www.ipeadata.gov.br/>. Acesso em: 23 jun. 2017.

INSTITUTO DE PESQUISA ECONÔMICA APLICADA (IPEA). Diretoria de Estudos e Políticas Sociais. Políticas sociais: acompanhamento e análise n. 23. In:

Saúde. Brasília: Ipea, 2015. cap. 3. p. 117-179. Disponível em: <http://www. ipea.gov.br/portal/index.php?option=com_content\&view=article\&id=25812\& Itemid=9>. Acesso em: 23 jun. 2017.

MÂNICA, Fernando Borges. Teoria da reserva do possível: direitos fundamentais a prestações e a intervenção do Poder Judiciário na implementação de políticas públicas. Revista Eletrônica de Direito Administrativo Econômico, Salvador, n. 25, p. 1-17, fev./abr. 2011. Disponível em: <http://www.direitodoestado.com/ revista/REDAE-25-ABRIL-2011-FERNANDO-BORGES-MANICA.pdf >. Acesso em: 21 jun. 2017.

MENDES, Gilmar Ferreira; COELHO, Inocêncio Mártires; BRANCO, Paulo Gustavo Gonet. Curso de direito constitucional. São Paulo: Saraiva, 2008.

MORAES, Alexandre de. Direitos humanos fundamentais. 8. ed. São Paulo: Atlas, 2007.

Direito constitucional. 30. ed. São Paulo: Atlas, 2014.

NABAIS, José Casalta. A face oculta dos direitos fundamentais: os deveres e os custos dos direitos. Disponível em: <http://www.egov.ufsc.br/portal/sites/ default/files/anexos/15184-15185-1-PB.pdf>. Acesso em: 21 jun. 2017.

QUEIROZ, Maria do Socorro Azevedo de. Judicialização dos direitos sociais prestacionais: a efetividade pela interdependência dos direitos fundamentais na Constituição brasileira. Curitiba: Juruá, 2011.

SARLET, Ingo Wolfgang. A eficácia dos direitos fundamentais. 3. ed. Porto Alegre: Liv. Advogado, 2003.

SILVA, Jose Afonso da. Curso de direito constitucional positivo. 34. ed. São Paulo: Malheiros, 2011. 
SISCHES, Luis Recaséns. Nueva filosofía de la interpretación del derecho. México: Porrúa, 1998.

TORRES, Ricardo Lobo. 0 direito ao mínimo existencial. Rio de Janeiro: Renovar, 2009.

VITA, Jonathan Barros; SILVA, Karina Zanin da. O princípio da reserva do possível e o direito fundamental à saúde. Revista Jurídica Cesumar, Maringá, v. 14, n. 1, p. 241-264, jan./jun. 2014. Disponível em: <http://periodicos.unicesumar. edu.br/index.php/verjuridica/article/view/3439>. Acesso em: 20 jun. 2017.

Recebido em: 9-8-2017

Aprovado em: 24-1-2018

\section{Oreonnilda de Souza}

Mestre em Empreendimentos Econômicos, Desenvolvimento e Mudança Social pela Universidade de Marília - UNIMAR; especialista em direito material e processual do trabalho pelo Centro Universitário de Rio Preto - UNIRP; pedagoga pelo UNIRP; docente no curso de direito do UNIRP; advogada militante (consultivo e contencioso); sócio-proprietária do escritório HILKNER Advogados. E-mail: oreonnilda@gmail.com

Universidade de Marília (UNIMAR). Programa de Mestrado em Direito. Av. Hygino Muzzi Filho no 1001. CEP 17.525-902. Campus Universitário. MARILIA - SP

\section{Lourival José de Oliveira}

Doutor em direito das relações sociais pela Pontifícia Universidade Católica de São Paulo - PUC-SP; mestre em direito das relações sociais pela Universidade Estadual de Londrina - UEL; professor permanente do Programa de Doutorado/mestrado em Direito da Universidade de Marília - UNIMAR; professor associado da UEL no curso de graduação em direito; advogado. E-mail:

Universidade de Marília (UNIMAR). Programa de Mestrado em Direito. Av. Hygino Muzzi Filho no 1001. CEP 17.525-902. Campus Universitário. MARILIA - SP 
